\title{
Diseño de una rúbrica para evaluar trabajos en grupo: revisión y reflexión.
}

\author{
María Dolores Mauricio ${ }^{a}$, Eva Serna ${ }^{b}$, Soraya L. Vallés ${ }^{a}$, Martín Aldasoro ${ }^{a}$ y José M. \\ Vila
}

${ }^{a}$ Departamento de Fisiología, Universitat de Valencia. M.dolores.mauricio@uv.es, Lilian.valles@uv.es, aldasoro@uv.es y vila@uv.es. ${ }^{b}$ Departamento de Patología, Universitat de Valencia. Eva.serna@uv.es

\begin{abstract}
Rubrics are scoring guides that, when done right, offer teachers some advantages while qualifying. Our experience consisted in elaborate a rubric to evaluate the group work and analyze the qualifications obtained, broken down by sections and compare them with weight given to each section within the rubric. The aim of our study was to analyze whether the rubric used was discriminatory, as well as, to detect strengths and weaknesses in the designed rubric. The results showed a wide range of qualifications once evaluated with our rubric. $80 \%$ of rubric featured well-defined descriptors and of the remaining 20\%, 10\% was evaluated by students and the other 10\% was too subjective because evaluation criteria were not well-defined. In conclusion, our rubric was discriminatory and therefore suitable to evaluate the goup work of our students. Sections with fewer descriptors were less discriminatory than those with defined criteria. Generally a wide range of qualifications demonstrate the suitability of the rubric used.
\end{abstract}

Keywords: evaluation, analytical rubric, group work.

\section{Resumen}

Las rúbricas de evaluación son guías de puntuación que bien elaboradas ofrecen al profesorado unas ventajas a la hora de calificar. En nuestra experiencia hemos diseñado una rúbrica para evaluar trabajos en grupo y hemos analizado las calificaciones obtenidas, desglosadas por apartados y comparándolas con el peso otorgado a cada apartado dentro de la rúbrica. La finalidad de este estudio era analizar si la rúbrica diseñada era discriminatoria, así como detectar los puntos débiles de la misma para reflexionar sobre las mejoras que se le podrían practicar. Los resultados mostraron un amplio abanico de calificaciones evaluando con la rúbrica diseñada. El $80 \%$ de la rúbrica contó con descriptores bien definidos y del $20 \%$ restante, un 10\% fue evaluado por los alumnos y el otro $10 \%$ resultó demasiado subjetivo por no tener bien definidos los criterios de evaluación, considerándose éste un punto débil de la misma y susceptible de mejora. En términos generales, la rúbrica utilizada ofreció notas discriminatorias entre grupos demostrando la idoneidad de su diseño.

Palabras clave: evaluación, rúbrica analítica, trabajo en grupo. 


\section{Introducción}

Las rúbricas son guías de puntuación que describen las características específicas de una tarea en varios niveles de rendimiento, con el fin de clarificar lo que se espera del trabajo del alumno, valorar su ejecución, así como facilitar la retroalimentación (Andrade, 2005) (Mertler, 2001).

Se podrían definir dos tipos de rúbricas. Las rúbricas globales u holísticas, definidas como aquellas que valoran el conjunto de la tarea, mediante la utilización de descriptores generales y que proporcionan información global del alumno y las rúbricas analíticas que se centran en tareas de aprendizaje concretas y necesitan un diseño más pormenorizado desglosando sus componentes para obtener una calificación total. Se recomiendan las rúbricas analíticas cuando hay que identificar los puntos fuertes y débiles, tener información detallada, valorar habilidades complejas y promover que los estudiantes autoevalúen su desempeño (Gatica-Lara, 2013).

Las rúbricas ofrecen ventajas tanto para los alumnos como para el profesor, así podemos destacar que con estos instrumentos, los alumnos tienen más información, pueden autoevaluarse, ya que conocen los criterios de evaluación y aumenta la responsabilidad del alumnado, pues en función de los criterios expuestos pueden revisar sus trabajos antes de entregarlos al profesor. Además las rúbricas ayudan a los alumnos a pensar en profundidad y facilitan la comprensión global del tema. En cuanto a las ventajas que estos instrumentos ofrecen al profesorado cabe destacar que son fáciles de usar y de explicar a los alumnos e incrementan la objetividad en la evaluación; también proporcionan retroalimentación sobre la eficacia de la metodología docente empleada y se ajustan a las exigencias del proceso de evaluación por competencias (Martinez-Rojas, 2008). Sin embargo, las rúbricas de evaluación no están exentas de desventajas como el elevado tiempo empleado en su elaboración o el riesgo de hacer un mal diseño que no identifique correctamente los criterios de evaluación (Pophan, 1997). En este sentido, existen en la literatura un elevado número de tutoriales que indican paso a paso cómo elaborar correctamente una rúbrica, también encontramos aplicaciones informáticas con las que podemos elaborar una rúbrica electrónica (e-rúbrica). Basándonos en el trabajo publicado por Malini (Malini, 2010), el proceso para elaborar rúbricas debe contener cuatro pasos:

1. Determinar los objetivos del aprendizaje.

2. Identificar los elementos o aspectos a valorar.

3. Definir descriptores, escalas de calificación y criterios.

4. Determinar el peso de cada criterio.

5. Revisar la rúbrica diseñada y reflexionar sobre su impacto educativo.

En la literatura podemos encontrar información acerca de la elaboración de rúbricas, incluso herramientas informáticas destinadas a la confección de las mismas, sin embargo, hay pocos estudios que analicen los resultados obtenidos a partir de la utilización de una rúbrica concreta y reflexionen sobre su impacto.

\section{Objetivos}

El objetivo de nuestro estudio no es detallar cómo se hace una rúbrica, sino valorar globalmente si la rúbrica que hemos confeccionado es discriminatoria y por tanto adecuada para evaluar a nuestros estudiantes. Para alcanzar este objetivo nos planteamos en primer

(cc) EY-NC-ND 2016, Universitat Politècnica de València 
lugar analizar cada apartado de la rúbrica analítica que hemos confeccionado, justificando el peso que se le ha otorgado a cada uno de ellos. En segundo lugar, valorar el impacto educativo, obteniendo las calificaciones tanto globales, como por apartados, y comparando estos datos con los porcentajes otorgados a cada apartado de la rúbrica.

\section{Desarrollo de la innovación}

La actividad que hemos evaluado mediante la rúbrica diseñada se planteó como un trabajo de investigación por equipos. Se llevó a cabo en la asignatura de Fisiología impartida en el primer curso del Grado de Podología de la Universitat de València. Participaron un total de 59 alumnos divididos en 14 equipos (11 grupos de 4 personas y 3 grupos de 5 integrantes). Cada grupo debía realizar un manuscrito en consenso que acabarían exponiendo y defendiendo oralmente ante toda la clase. Todos los equipos coincidían en el punto de partida: la hipótesis "los estrógenos podrían modular el flujo sanguíneo y proteger a las mujeres a nivel cardiovascular". También se les proporcionaban unos breves antecedentes del tema y las directrices para buscar la información. Durante todo el proceso el profesor estaba a disposición de los estudiantes y los orientaba.

Se calificó la actividad propuesta usando una rúbrica analítica diseñada en consenso por los profesores de la asignatura en base a la experiencia docente y siguiendo las recomendaciones de Malini y colaboradores (Malini, 2010). La rúbrica confeccionada contenía 4 bloques (Fig 1).

1. Manuscrito, $60 \%$ de la nota

2. Exposición oral, $20 \%$ de la nota

3. Participación en el equipo, $10 \%$ de la nota

4. Actitud, $10 \%$ de la nota

El primer bloque, "Manuscrito", analiza el trabajo escrito presentado por el grupo, valora la estructura (1 punto) y el contenido (5 puntos) (Fig. 1). La estructura debe contener un índice y todos los apartados indicados previamente por el profesor (introducción, hipótesis y objetivos, metodología, protocolo y resultados y bibliografía), así como no exceder del número de páginas solicitado y usar el tipo de letra acordado. El subapartado de "Contenido" se divide a su vez en cinco partes que se evalúan de la siguiente manera:

- Introducción: los alumnos deben relacionar los estrógenos con el flujo sanguíneo. Deben explicar esta conexión a través del endotelio y en concreto de la participación del factor relajante endotelial conocido como óxido nítrico. Por lo que las palabras clave que debe contener esta introducción son estrógenos, flujo sanguíneo, endotelio y óxido nítrico. $\mathrm{Si}$ todos estos conceptos están bien explicados y relacionados, la introducción obtiene la máxima puntuación, 2 puntos.

- La hipótesis y los objetivos vienen dados por el profesor, por lo que todos los alumnos disponen de esta información y no se evalúa.

- Metodología. Aquí les pedimos que expliquen el fundamento de la técnica de pletismografía por oclusión venosa. Deben indicar que el fundamento de esta técnica es la hiperemia reactiva y explicar el concepto correctamente. La puntuación máxima es de 0.5

(c)) EY-NC-ND 2016, Universitat Politècnica de València

Congreso In-Red (2016) 
Diseño de una rúbrica para evaluar trabajos en grupo: revisión y reflexión.

Figura 1. Rúbrica analítica utilizada en la evaluación

\begin{tabular}{|c|c|c|c|c|c|}
\hline & & & Insuficiente & Buena & Excelente \\
\hline \multirow{5}{*}{$\begin{array}{l}\text { Manuscrito } \\
(60 \%)\end{array}$} & Estructura & Hasta 1 punto & $\begin{array}{l}\text { No se } \\
\text { corresponde con } \\
\text { la solicitada }\end{array}$ & $\begin{array}{l}\text { Se cumple } \\
\text { parcialmente }\end{array}$ & $\begin{array}{l}\text { Se cumple en su } \\
\text { totalidad }\end{array}$ \\
\hline & \multirow{4}{*}{$\begin{array}{l}\text { Contenido } \\
\text { Hasta } 5 \\
\text { puntos }\end{array}$} & Hasta 2 puntos & \multicolumn{3}{|c|}{$\begin{array}{l}\text { Introducción: palabras clave bien definidas e } \\
\text { interrelacionadas correctamente }\end{array}$} \\
\hline & & $\begin{array}{l}\text { Hasta } 0.5 \\
\text { puntos }\end{array}$ & \multicolumn{3}{|c|}{$\begin{array}{l}\text { Metodología: explicar correctamente el fundamento } \\
\text { fisiológico en el que se basa }\end{array}$} \\
\hline & & Hasta 2 puntos & \multicolumn{3}{|c|}{$\begin{array}{l}\text { Protocolo y resultados: proponer un protocolo detallado y } \\
\text { correcto así como resultados esperados y debidamente } \\
\text { justificados. Se valora el aporte de gráficos que plasmen } \\
\text { los posibles resultados }\end{array}$} \\
\hline & & $\begin{array}{l}\text { Hasta } 0.5 \\
\text { puntos }\end{array}$ & \multicolumn{3}{|c|}{$\begin{array}{l}\text { Bibliografía: se valora la existencia de bibliografía en el } \\
\text { formato correcto, así como la fiabilidad de la fuente }\end{array}$} \\
\hline \multirow[t]{2}{*}{$\begin{array}{l}\text { Exposición oral } \\
(20 \%)\end{array}$} & $\begin{array}{l}\text { Diseño y } \\
\text { presentación }\end{array}$ & $\begin{array}{l}\text { Hasta } 1.5 \\
\text { puntos }\end{array}$ & $\begin{array}{l}\text { Sencillo y básico } \\
\text { con pocas } \\
\text { imágenes }\end{array}$ & $\begin{array}{l}\text { Imágenes y } \\
\text { esquemas } \\
\text { propios }\end{array}$ & $\begin{array}{l}\text { Material } \\
\text { multimedia }\end{array}$ \\
\hline & Defensa & $\begin{array}{l}\text { Hasta } 0.5 \\
\text { puntos }\end{array}$ & $\begin{array}{l}\text { No responde } \\
\text { correctamente }\end{array}$ & $\begin{array}{l}\text { Responde } \\
\text { parcialmente } \\
\text { bien }\end{array}$ & $\begin{array}{l}\text { Aclara y } \\
\text { defiende los } \\
\text { conceptos } \\
\text { correctamente }\end{array}$ \\
\hline $\begin{array}{l}\text { Participación en } \\
\text { el equipo }(10 \%)\end{array}$ & $\begin{array}{l}\text { Nota } \\
\text { individual }\end{array}$ & Hasta 1 punto & \multicolumn{3}{|c|}{$\begin{array}{l}\text { Valoración de cada miembro del grupo por el resto de } \\
\text { compañeros, en una escala de } 1-10\end{array}$} \\
\hline Actitud (10\%) & & Hasta 1 punto & $\begin{array}{l}\text { Poco interés. No } \\
\text { consulta al } \\
\text { docente }\end{array}$ & $\begin{array}{l}\text { Consulta al } \\
\text { docente sólo al } \\
\text { final del } \\
\text { proceso }\end{array}$ & $\begin{array}{l}\text { Muestra interés y } \\
\text { responsabilidad } \\
\text { durante todo el } \\
\text { proceso }\end{array}$ \\
\hline
\end{tabular}

- Protocolo y resultados: los alumnos deben conocer las variaciones que se dan en la concentración plasmática de estrógenos durante el ciclo menstrual. Deben explicar las fluctuaciones hormonales durante el ciclo centrándose en los niveles de estrógenos. Deben deducir que días serán los más apropiados para hacer las mediciones de flujo sanguíneo e indicarlo en el protocolo experimental. Después tienen que redactar los resultados que esperan obtener y justificarlos. Se valora que el trabajo contenga aportaciones como

(cc) EY-NC-ND 2016, Universitat Politècnica de València 
esquemas o incluso gráficas con los resultados esperados que muestren que el alumnado ha alcanzado el grado de comprensión requerido. Si lo hacen correctamente este apartado son 2 puntos.

- Bibliografía: se evalúa hasta 0.5 puntos y se valora la existencia de bibliografía en el formato correcto, así como la fiabilidad de la fuente.

El segundo bloque "Exposición oral", con un máximo de 2 puntos, valora la presentación hasta 1.5 y la defensa hasta 0.5 puntos. Se evalúa que las diapositivas sean dinámicas, con poca letra y más elementos visuales, imágenes o esquemas, así como la fluidez al explicar los conceptos. La defensa del trabajo se valora mediante las respuestas a las preguntas que hace el profesor al finalizar la exposición oral.

El tercer bloque "Participación en el equipo", valora la participación e implicación individual de cada miembro en el grupo de trabajo. En este apartado cada alumno obtiene una calificación por parte de sus compañeros de equipo. Supone un $10 \%$ de la nota.

El cuarto bloque "Actitud" supone la evaluación continua por parte del profesor que ha tutelado el equipo y se tiene en cuenta aspectos como el interés del grupo por la realización del trabajo, el número y la calidad de las tutorías que han solicitado con el profesor, así como si lo han hecho desde el principio del proceso o lo han dejado para el final.

\section{Resultados}

Utilizando la rúbrica diseñada se evaluaron los 14 equipos y se obtuvo una nota media de 6,8 contando con 4 sobresalientes, 6 notables y 4 aprobados. Si analizamos las calificaciones por bloques se observa que el bloque 2. "Exposición oral" obtiene la menor puntuación, un 6,9 de media. En la tabla 1 se muestran las calificaciones medias obtenidas por los 14 grupos en los cuatro bloques de la rúbrica.

Tabla 1. Calificaciones medias de los cuatro bloques de la rúbrica obtenidas por los 14 grupos de estudio

\begin{tabular}{llcll}
\hline & Bloque & Nota media & $\begin{array}{l}\text { Apartados dentro } \\
\text { del bloque }\end{array}$ & Nota \\
\hline 1. & Manuscrito & 7.5 & Estructura & 9.5 \\
& & & Contenido & 7.1 \\
2. & Exposición oral & 6.9 & Presentación & 6.1 \\
& & & Defensa & 9.2 \\
3. $\begin{array}{l}\text { Participación en } \\
\text { el equipo }\end{array}$ & 8.0 & Nota individual & \\
4. & Actitud & 10 & & \\
\hline
\end{tabular}

(c)) BY-NC-ND 2016, Universitat Politècnica de València

Congreso In-Red (2016) 
El bloque 1. Manuscrito obtuvo una puntuación media de 7.5, con 5 sobresalientes, 3 notables, 5 aprobados y un suspenso (Tabla 2). Este bloque se dividía a su vez en dos apartados, estructura y contenido. En cuanto a la estructura, a pesar de venir detallada en las instrucciones del trabajo, no todos los grupos la cumplieron, así 4 grupos obtuvieron 0.9 puntos, un grupo 0.8 puntos y el resto la máxima puntuación (1 punto). En cuanto al contenido, la nota media de la clase fue un 7.1 que se repartió en 5 sobresalientes, 3 notables, 2 aprobados y 4 suspensos (Tabla 2).

Tabla 2. Calificaciones correspondientes al Bloque 1. Manuscrito, desglosadas en los dos apartados, estructura y contenido.

\begin{tabular}{cccc}
\hline & Manuscrito & Estructura & Contenido \\
\hline Nota media & 7.5 & 9.5 & 7.1 \\
Sobresaliente & $5(36 \%)$ & $13(93 \%)$ & $5(36 \%)$ \\
Notable & $3(21 \%)$ & $1(7 \%)$ & $3(21 \%)$ \\
Aprobado & $5(36 \%)$ & 0 & $2(14 \%)$ \\
Suspenso & $1(7 \%)$ & 0 & $4(29 \%)$ \\
\hline
\end{tabular}

En contenido, a su vez, se estructuraba en cuatro apartados, que obtuvieron las siguientes calificaciones (Tabla 3):

- Introducción. Este apartado obtuvo una media de 8.3 donde predominaron los sobresalientes (7 grupos), seguidos de los notables (7 equipos).

- Metodología. La nota media de los 14 grupos fue un 5.6, con 6 suspensos, 1 aprobado, 1 notable y 6 sobresalientes.

- Protocolo y resultados. La calificación media fue de 5.5 contando con 5 suspensos, 1 aprobado, 5 notables y 3 sobresalientes.

- Bibliografía. En este apartado 13 grupos obtuvieron sobresaliente y uno suspenso por no reflejar el apartado solicitado en el manuscrito. La nota media fue de 9.2.

Tabla 3. Calificaciones del Contenido, desglosado en subapartados.

\begin{tabular}{lcccc}
\hline & Introducción & Metodología & Protocolo/Resultados & Bibliografía \\
\hline Nota media & 8.3 & 5.6 & 5.5 & 9.2 \\
Sobresaliente & $7(50 \%)$ & $6(43 \%)$ & $3(21 \%)$ & $13(93 \%)$ \\
Notable & $4(29 \%)$ & $1(7 \%)$ & $5(36 \%)$ & 0 \\
Aprobado & $3(21 \%)$ & $1(7 \%)$ & $1(7 \%)$ & 0 \\
Suspenso & 0 & $6(43 \%)$ & $5(36 \%)$ & $1(7 \%)$ \\
\hline
\end{tabular}

(cc) EY-NC-ND 2016, Universitat Politècnica de València 
El bloque 2 "Exposición oral" obtuvo una nota media de 6.9 con 4 sobresalientes, 3 notables, 5 aprobados y 2 suspensos. La presentación del trabajo obtuvo una calificación inferior a la defensa siendo las notas medias de 6.1 y 9.3 respectivamente. En la presentación 3 grupos obtuvieron sobresaliente, 2 equipos notable, 3 consiguieron un aprobado y 6 suspendieron este apartado. En cuanto a la defensa, las calificaciones fueron 10 sobresalientes y 4 aprobados (Tabla 4 ).

Tabla 4. Calificaciones correspondientes al Bloque 2. Exposición oral, desglosadas en los dos subapartados, presentación y defensa.

\begin{tabular}{lccc}
\hline & Exposición oral & Presentación & Defensa \\
\hline Nota media & 6.9 & 6.1 & 9.3 \\
Sobresaliente & $4(29 \%)$ & $3(21 \%)$ & $10(71 \%)$ \\
Notable & $3(21 \%)$ & $2(14 \%)$ & 0 \\
Aprobado & $5(36 \%)$ & $3(21 \%)$ & 0 \\
Suspenso & $2(14 \%)$ & $6(43 \%)$ & $4(29 \%)$ \\
\hline
\end{tabular}

Las puntuaciones del bloque 3 fueron obtenidas mediante una encuesta que rellenaron los alumnos en la que se les pedía que calificaran a sus compañeros de equipo del 1 al 10 en base a su implicación en la confección del trabajo. La nota media fue de 8 con 30 sobresalientes, 20 notables, 6 aprobados y un suspenso.

Por último, se valoró la actitud del grupo según criterio del profesor considerando la cantidad y calidad de las tutorías a las que había acudido cada grupo. Se otorgó la máxima nota a todos los grupos.

\section{Conclusiones}

La finalidad de nuestro estudio era revisar la rúbrica diseñada y reflexionar sobre su impacto, analizando si el peso otorgado a cada apartado había sido el adecuado, una vez obtenidas las calificaciones. La nota media obtenida en la actividad fue de 6,9 destando que ninguno de los grupos suspendió. La rúbrica analítica utilizada se dividía en cuatro bloques, el manuscrito que suponía el $60 \%$ de la nota, la exposición oral, 20\%, la participación en equipo, $10 \%$ y la actitud, otro $10 \%$ de la nota final.

Analizando el bloque con más peso, el manuscrito, encontramos dos apartados, la estructura y el contenido. Pese a que el apartado de estructura, estaba claramente detallado en las instrucciones del trabajo, no todos los grupos consiguieron la máxima puntuación. Esto demuestra poco interés por parte de dichos equipos o bien que a una parte del alumnado le cuesta adaptarse, ya que se trata de alumnos de primer curso y la asignatura se imparte en el primer cuatrimestre. Algunos alumnos no sabían donde encontrar las instrucciones, que estaban en el aula virtual desde el primer día de clase. De todos modos, el personal docente toma nota para en próximos cursos reiterar que se respete la estructura

(cc)) BY-NC-ND 2016, Universitat Politècnica de València

Congreso In-Red (2016) 
del trabajo. Hay que resaltar que se restaban puntos por presentar el trabajo sin índice o alguno de los apartados indicados reiteradamente por el personal docente. Hubo 5 grupos que presentaron el trabajo sin índice o sin alguno de los apartados, por eso no obtuvieron la máxima nota. Dada la dificultad que entrañaban otros apartados del trabajo, se consideró dar un punto a la estructura, aunque pudiera parecer excesivo. Con los resultados obtenidos podemos concluir que fue una idea acertada ya que subió la nota a todos los grupos. De hecho, la nota media del Bloque 1. "Manuscrito" fue de 7.5 mientras que la nota del apartado "contenido" fue de media 7.1. Estos 0.4 puntos de diferencia fueron gracias a la valoración al alza del apartado de "estructura".

De los 6 puntos que aportaba el bloque 1."Manuscrito", 5 correspondían al apartado de contenido. Dentro de éste, tenían el mismo peso los apartados de "Introducción” y " Protocolo y resultados", ya que en ambos se concentraban la mayoría de los objetivos de aprendizaje que perseguía el trabajo. La introducción debía contener unas palabras clave que consistían en los conceptos impartidos en la teoría que se pretendían afianzar. Los alumnos no sólo debían describirlos, sino interrelacionarlos entre sí. Se solicitaron muchas tutorías por este motivo y finalmente fue un apartado con una buena calificación, 8.3, de media y contando con un $50 \%$ de sobresalientes. Cabe destacar que no hubo ningún grupo que suspendiera el apartado de introducción. Estos buenos resultados demuestran que nuestro alumnado es capaz de buscar la información, entenderla, procesarla y plasmarla por escrito con éxito. Por el contrario, el apartado de "Protocolo y resultados" entrañaba un grado de dificultad elevado para nuestros estudiantes, pues suponía haber comprendido la metodología y demostrarlo mediante el diseño de un protocolo experimental. Además tenían que aventurarse a especular posibles resultados. En definitiva, implicaba el acercamiento al método científico, teniendo que aplicar lo aprendido para comprobar una hipótesis. Este fue el apartado que más dudas generó entre los estudiantes y el primer motivo de solicitud de tutorías. Finalmente los resultados mostraron una nota media para este apartado de 5.5 que constataba la dificultad del mismo. En este caso sí que hubo suspensos, un $36 \%$. Al otorgarse el mismo peso en la rúbrica de evaluación a los apartados de "Introducción" (con una nota media de 8.3) y al apartado de "Protocolo y resultados" (nota media de 5.5) se compensaron las calificaciones.

En cuanto al apartado de "Metodología" cabe destacar que se valoró con tan sólo 0,5 puntos porque considerábamos que su correcto entendimiento era complicado para el nivel de nuestros estudiantes, por lo que pretendíamos que tuvieran una idea muy básica y se centraran en explicar correctamente el fundamento fisiológico de la pletismografía de oclusión venosa. De hecho, les indicamos a los estudiantes que podían haber otras técnicas también adecuadas para resolver la hipótesis pero la que nosotros planteábamos tenía la ventaja de no ser invasiva y era la que tenían que utilizar. De este modo, les creábamos un escenario virtual en el que tenían que manejarse: ellos eran un equipo de investigadores con una hipótesis y una única técnica para resolversa. Los resultados de la rúbrica en este apartado muestran una nota media de 5.6, con un $43 \%$ de suspensos que refleja la dificultad del mismo, aunque cabe resaltar que otro $43 \%$ fueron sobresalientes, demostrando que la exigencia de este apartado se podía alcanzar, es decir, no estábamos pidiendo a nuestros alumnos algo extremadmente difícil y se estaba evaluando acorde a su nivel. Con el mismo peso que la metodología ( 0,5 puntos) se valoró el apartado de "Bibliografía". Se hizo especial hincapié en la búsqueda de información contrastada puesto que por la experiencia 
del equipo docente en anteriores cursos suele ser un punto débil de los manuscritos. El resultado fue muy satisfactorio, un 9.2 de media. De nuevo, podemos concluir que la rúbrica de evaluación estaba compensada otorgando el mismo peso a los apartados de "Metodología" y "Bibliografía" con notas medias de 5.6 y 9.2 respectivamente.

La nota global del apartado 1.2 Contenido fue de 7.1, lo que sugiere que se trataba de un tema de dificultad apropiada para estos alumnos e indica que la rúbrica de evaluación era adecuada, pues aplicando los mismos criterios obtuvimos un amplio abanico de calificaciones. En resumen, el bloque 1. Manuscrito obtuvo una nota media de 7.5, evaluando con la rúbrica diseñada, que demostró estar compensada al valorar con el mismo porcentaje apartados con distinta dificultad.

En cuanto al Bloque 2. Exposición oral, la nota media de los 14 grupos fue 6.9. Dentro de este bloque los apartados de presentación y defensa obtuvieron un 6.1 y un 9.3 respectivamente. El bloque 2 suponía el $20 \%$ de la nota del trabajo, es decir se podían obtener como máximo 2 puntos, de los cuales 0.5 se destinaron a la presentación y 1.5 a la defensa. Los profesores decidimos otorgarle mayor peso a la defensa que a la presentación basándonos en nuestra experiencia previa con estos alumnos. Se trata de estudiantes de primer curso que en su mayoría no han recibido formación previa con respecto a cómo se realiza una presentación oral. En el plan de estudios vigente en el Grado de Podología existen asignaturas en las que se tratan estas competencias específicamente pero se cursan hacia el final de la carrera, orientadas a hacer una buena presentación en el Trabajo de Fin de Grado. Por falta de tiempo, nosotros no podemos profundizar en todos los aspectos de la misma manera y en el caso de cómo hacer la exposición sólo podemos orientarles con unas directrices básicas, así que a la hora de evaluar hemos de ser consecuentes y otorgarle un peso menor que a otros apartados que hemos podido trabajar mejor. Además, los alumnos suelen consultarnos acerca del contenido más que acerca de cómo presentarlo, quizás porque no son conscientes de la importancia de hacer una buena presentación. En términos generales las presentaciones tenían pocas imágenes, demasiada letra y no eran fluidas. Así se reflejó en las calificaciones, el $43 \%$ de los grupos suspendieron. Sin embargo, la defensa en grupo, es decir la respuesta por cualquiera de los miembros del equipo a una pregunta lanzada por el profesor, fue de sobresaliente en el $71 \%$ de los casos. El hecho de otorgarle más peso a la defensa que a la presentación se tradujo en un aumento de la nota media del bloque 2 .

El bloque 3. "Participación en equipo" desveló algunos casos en los que la participación fue desigual. Nos pareció necesario valorar este apartado de forma individual, ya que en experiencias anteriores habíamos recibido quejas de algunos alumnos sobre el distinto grado de implicación en el trabajo y lo injusto que les parecía que no se reflejase en la nota final. Otorgarle menos de un $10 \%$ no era significativo, pues apenas modificaba la nota final y darle más de un $10 \%$ podía ser peligroso, por dejar en manos de los propios alumnos un porcentaje importante de la nota, susceptible a amistades o enemistades y por tanto no objetivo. Además, al tratarse de un trabajo en grupo, la nota tenía que ser muy similar para todos los integrantes, pues se pretendía potenciar el trabajo cooperativo. Si se le daba un $10 \%$ a este bloque, las diferencias entre miembros del mismo equipo podían llegar a ser como máximo de 1 punto en la nota final de la actividad, así que nos pareció apropiado otorgarle un $10 \%$. Los resultados demostraron que, en líneas generales, existía 
mucho compañerismo, pues la calificación media que un alumno recibía por parte de sus compañeros era de notable alto (8). Por lo que prácticamente todos los integrantes del grupo tuvieron finalmente la misma nota.

En cuanto al último bloque 4. "Actitud", se valoró muy positivamente a todos los equipos. La mayoría de grupos solicitaron varias tutorías bien virtuales, bien presenciales. Es cierto que en algunas tutorías presenciales no estaban todos los integrantes pero este punto era delicado juzgarlo pues el profesor no conocía el motivo de la ausencia. Además ya se valoraba la cooperación en el grupo en el apartado anterior. Hubo grupos que solicitaron más tutorías que otros pero tampoco se podía calificar por el número de estas, pues aquellos equipos que no solicitaron tantas tutorías podían tener como motivo haberlo entendido todo con leer detenidamente las instrucciones. La calidad de las tutorías era similar de unos equipos a otros y acorde con el nivel formativo de nuestro alumnado. Al intentar evaluar este apartado nos dimos cuenta de que los criterios de evaluación se debían haber definido con mayor obejtividad. Este bloque no estuvo bien diseñado en la rúbrica y habría que mejorarlo o eliminarlo. Puesto que se trató de un error de los docentes a la hora de elaborar la rúbrica y no encontrábamos con los descriptores usados diferencias significativas entre grupos decidimos otorgar la máxima puntuación a todos ellos.

Como conclusión final, podemos afirmar que, en líneas generales, la rúbrica diseñada fue adecuada, ya que obtuvimos resultados discriminatorios, tanto en el bloque 1 como en el bloque 2. Sin embargo, el bloque 4 que contaba con menos descriptores y criterios de evaluación quedó valorado de forma muy subjetiva y no sirvió para discriminar entre grupos. Afortunadamente, la suma de los bloques 1 y 2 suponía el $80 \%$ de la nota y por tanto las calificaciones finales sí fueron discriminatorias.

Cabe resaltar que la rúbrica fue especialmente válida como elemento evaluador en el bloque 1 porque estaban muy detallados los objetivos de aprendizaje, los descriptores y los criterios de calificación. Este bloque fue el que más costó de diseñar y evaluar, pero el que mejores resultados de calificación nos proporcionó.

Así pues, una vez realizado el análisis de la rúbrica empleada podemos concluir que ésta fue apropiada para la tarea de evaluar los trabajos grupales y nos sirvió para detectar los puntos débiles y mejorarlos de cara al próximo curso.

\section{Referencias}

ANDRADE, H. "Teaching with rubrics - The good, the bad, the ugly" en College Teaching. (2005, 53 (1), 27-30.) DOI:10.3200/CTCH.53.1.27-31

GATICA-LARA F. “¿Cómo elaborar una rúbrica?” en Investigación en Educación Médica. (2013, 2(1), 61-65).

MALINI, RY, ANDRADE H. "A review of rubric use in higher education" en Assessment \& Evaluation in Higher Education. (2010,35(4),435-448).

MARTINEZ-ROJAS, JG. “Las rúbricas en la evaluación escolar: su contrucción y uso” en Avances en Medición. (2008, 6, 129-138). 
MERTLER, CA. (2001). "Designing scoring rubrics for your classroom" en Practical Assessment, Research \& Evaluation. $(2001,7,25) .<$ http://PAREonline.net/getvn. asp? $\mathrm{v}=7 \& \mathrm{n}=25>$ Consulta: 29 de febrero de 2016].

POPHAN, WJ. "What's wrong and what's right with rubrics?" en Educational Leadership. (1997, $55(2), 72-75)$. 